\title{
Distributed Agent-based IP Location System Framework Design
}

\author{
http://dx.doi.org/10.3991/ijoe.v9iS7.3185 \\ Feng-Yu Lin ${ }^{1}$, Yeali S. Sun ${ }^{1}$ and Meng Chang Chen ${ }^{2}$ \\ ${ }^{1}$ National Taiwan University, Taipei, Taiwan \\ ${ }^{2}$ Institute of Information Science, Academia Sinica, Taipei, Taiwan
}

\begin{abstract}
Computer crime causes significant impact and losses to society and the public security of countries, and even influences homeland security. From previous lessons, we know that the physical location of computer criminals plays an important role in combat with computer crime, including IP Traceback and IP Location. Literature review shows that there have been many studies of the topic of IP Traceback. However, the most critical IP Location has not yet been thoroughly discussed, and existing IP Location approaches, as based on end-to-end delay measurement from a set of landmarks, fail to outperform much simpler techniques, and the error of these approaches is strongly determined by the distance to the nearest landmark, even when triangulation is used to combine estimates from different landmarks. In view of this, this study uses the concept of IP Location and Network Forensics to propose the distributed agent-based IP Location system framework in order that the "position" of the criminal can be traced, and identity can be deduced by this mechanism, when cybercriminal behavior occurs. The result of actual implementation in WiMAX networks shows that the accuracy of IP Location can be the coverage area of a base station (in radius of $150-500 \mathrm{~m}$ in urban areas).
\end{abstract}

Index Terms-Cybercrime, Data Retention, IP Location, Network Forensics.

\section{INTRODUCTION}

Computer crime refers to any crime that involves a computer (IP device) and a network [1]. The computer (IP device) maybe have been used in the commission of a crime (ex. Cyberstalking, Fraud, Identity theft, Information warfare, Phishing scams), or it may be the target (ex. Computer viruses, Denial-of-service attacks, Malware) [2]. Such behavior causes significant impact and losses to society and the public security of countries, and even influences homeland security.

From previous lessons, knowing the physical locations of criminals is essential to fighting Computer Crime, including two important topics, IP Traceback and IP Location. IP Traceback is the critical ability of identifying sources of attacks and instituting protection measures for the Internet. Most existing approaches to this problem have been tailored toward DoS attack detection, which has been widely discussed in literature [3-15]. However, there has not yet been a sound solution to the most critical problem of IP Location.

IP Location refers to the process of finding the physical location of an Internet host [16]. It is currently proposed, or in use for a wide variety of purposes, including targeted marketing, restricting digital content sales to authorized jurisdictions, and security applications, such as reducing credit card fraud [17]. This is a difficult problem, even putting mobility aside, as the decentralized management of the Internet means that there is no authoritative database of host locations. The databases that do exist are derived by combining a mix of sources (including DNS LOC records, who the site is registered to, and DNS hostname parsing rules), which are all manually maintained, and thus, subject to inconsistencies and outdated information [16].

Current IP Location schemes [18-21] are primarily delay-measurement based. In these schemes, there are a number of landmarks with known locations. Delays from a targeted client to landmarks are measured, and the targeted client is mapped to a location inferred from the measured delays. However, most such schemes are based on the assumption of a linear correlation between networking delay and the distance between targeted client and landmark. The strong correlation has been verified in some regions of the Internet, such as North America and Western Europe [18] [22]. However, as pointed out in literature [22], Internet connectivity around the world is very complex, and such strong correlation may not apply to the Internet everywhere [23]. Due to the difficulty of finding uniform landmarks everywhere, these algorithms will typically work poorly for a fraction of targets, and there are estimates that are more than $1000 \mathrm{~km}$ off in our US-based experiments [16].

The proposed distributed agent-based IP Location system framework (IP Location mechanism) is based on the concepts of IP Location [24] and Network Forensics, and aim to trace the criminal's "location" and "identity" using this mechanism when a computer crime occurs. The logic of IP Location and individualization is that, in an environment of an integrated fixed network, mobile telecommunication network 3/3.5G, WiMAX, and next generation network IP Multimedia Subsystem (IMS), each related node in the network is confirmed, the DPI (Deep Packet Inspection) is in charge of accessing, copying, decoding, and saving necessary data retention for IP Location, in order to analyze the location of the IP Address, and associatively identity IP users, according to an IP Address, time, and the information record retained from using IP services on the Internet.

The remainder of this paper is organized as follows. Section II contains a review of related works. In Section III, this study will analyze the probable challenges to IP Location and the accompanying design implications. In Section IV, we present empirical evaluation for our IP Location mechanism and discuss its strengths and 
weaknesses. Finally, Section V summarizes our works and indicates areas for future research.

\section{RELATED WORKS}

During the last decade, various IP Location techniques have been proposed. In 2001 [16], V. N. Padmanabhan and L. Subramanian proposed three distinct techniques, GeoTrack, GeoPing, and GeoCluster, to perform IP Location. GeoTrack is based on the DNS names of the target host, or other nearby network nodes, using a traceroute tool to analyze IP Location. GeoPing is based on delay-measurement from geographically distributed locations to target hosts, and estimates the possible coordinates of the target host. GeoCluster infers target hosts' geographic location by combining partial host-tolocation mapping information and BGP prefix information, and is the most promising method, with various median errors from $28 \mathrm{~km}$ for well-connected university hosts to hundreds of kilometers for more heterogeneous set clients; however, mapping information must be manually and periodically updated.

In 2004, B. Gueye et al. proposed a Constraint-Based Location (CBG) approach, which employs a triangulationlike technique based on multilateration with distance constraints to infer geographic location. For accurate results, $\mathrm{CBG}$ estimates and removes additive delay distortion by self-calibrating the delay measurements. However, the median error distance product by the CBG approach can be reduced to less than $100 \mathrm{~km}$, at the $25 \mathrm{th}$ percentile, with 15 to $25 \mathrm{~km}$ to landmarks [17]. In addition, in 2006, Ethan Katz-Bassett et al. employed network topology information to improve location accuracy; however, the estimation errors for topology measurement are more than tens of kilometers [14]. Wong et al. [18] proposed a comprehensive framework in 2007, Octant, for determining possible region by positive and negative constraints within 22 miles (around $35.4 \mathrm{~km}$ ). In 2009 , Dan Li et al. proposed an IP Location mapping scheme, GeoGet, which involves moderately connected Internet regions by HTTP/Get probing for delay measurement, and the results show that it can accurately map 35.4\% of targeted clients to the city level, with a median error distance of approximately $120 \mathrm{~km}$ [19]. In addition, in 2011, Sandor Laki et al. proposed a probabilistic location approach, Spotter, for estimating the geographic location of Internet devices by handling all calibration points together to derive a common delay-distance model. Therefore, with the dataset of COGENT, and a large Tier1 ISP, Spotter improves the median error to $30 \mathrm{~km} \mathrm{[20].}$

For [14, 16-20], regardless of the dataset used, they are primarily delay-measurement based approaches, which try to measure the delays from a target client to landmarks, and then map the targeted client to a location inferred from the measured delays. As the delay problem of traffic congestion on a network is inevitable, an inherency feature of the Internet, it causes delay measurements with unpredictable errors in the round trip time for probing, which has the negative effect of random errors regarding geographic location. In addition, IP addresses behind a proxy or firewall cannot be detected for location.

There are some IP Location approaches, e.g. the WHOIS-based [23] and DNS-based approaches [22], which perform IP Location by querying the information on databases that store relative data or location regarding users when they registered with ISPs. However, there are some limitations, as the databases must be manually updated periodically, and is for fixed users only. They can be more accurate than the delay-measurement based approach, if the registry information offered by users is correctly updated; however, the problem of private IP addresses cannot be solved by a database based approach.

\section{DESIGN AND IMPLEMENTATION OF IP LOCATION MECHANISM}

In this section, we analyze the probable challenges to IP Location, and its accompanying design implications.

\subsection{The challenges}

\subsubsection{Nomadic}

The first challenge to IP Location is that the users are able to be nomadic and access the Internet from multiple and relatively arbitrary locations (Nomadicity). The main impact is that a static, predefined database cannot to be use for obtaining user location based on IP

Design Implication: In order to overcome the nomadic issue, an IP Location mechanism must be able to correlate the information of Internet endpoint or IP device (including geo information), e.g. MAC Address, dial-up account, and auxiliary number, to the IP used, and the information must be periodically updated by the network management database.

\subsubsection{Mobility}

The second challenge to IP Location is IP service with mobility, there is a category of Internet access technologies that supports full mobility of the user, and allows a user to connect to the Internet and access services even while traveling at high speeds. For example, in the Internet connection via $3 / 3.5 \mathrm{G}$, WiMAX and Wibro mobile broadband, the IP is fixed, but the location of the IP user continuously changes.

Design Implication: In order to overcome mobility issues, an IP Location mechanism must be able to obtain the data of IMSI/IMEI/MSISDN of the mobile Internet IP device corresponding to the Cell-ID, and to connect to the IP used.

\subsubsection{Anonymity}

Due to the DHCP and NAT mechanisms, IP cannot individualize a user, i.e. who was using the IP to connect to Internet at that time, severely impacting computer crime detection.

Design Implication: In order to overcome anonymity issues, an IP Location mechanism must execute data retention when DHCP/RADIUS server allocates an IP Address to some endpoint or IP device within some time interval and; if the Internet is connected via NAT, a mapping Table of Public IP and Private IP must be created, and the record is retained.

\subsection{Overview of the proposed Approach}

The distributed agent-based IP Location System framework, as proposed in this study, contains two key component devices, Distributed DPI Agents (DDA) and IP2Location Database (IPLD), and two XML-based Protocols for overcoming the aforesaid challenges. The Target Client using an IP device to connect to the Internet, as well as their physical location, can be deduced from the 


\section{SPECIAL FOCUS PAPER \\ DiSTRIBUTED AGENT-BASED IP LOCATION SYSTEM FRAMEWORK DESIGN}

Access Information collected by DDA and stored in IPLD, and from the Terminal Information obtained from the network management database.

\subsubsection{IP Location measurements and data retention}

The IP Location Measurements include the following two kinds of important information acquisition (TABLE I).

Termination Information: In this study, the information identifying a particular terminal is called Terminal Information, e.g. MAC Address, dial-up account, or auxiliary number. The Termination Information is provided by a network management database, also known as Provisioning Data. The ISP provider must provide the information related to user location (including geo information), which is transferred via Firewall to the Data Provisioning module inside the IP Location System.

Access Information: The information related to how the terminal accesses the network is called Access Information. In this study, DDA is responsible for providing Access Information, when provided with Terminal Information, which data often changes, especially in an environment of the dynamic acquisition of IP, and can be obtained from the existing network communication equipment (DHCP and/or RADIUS Server, AAA Server) or communication protocol packets.

As shown in Figure 1, the Distributed DPI Agents (DDA) is in charge of collecting Access Information, and sending the data to the IP2Location Database (IPLD) for integration and analysis. Each DPI Agent supervises specific nodes of specific networks (the mode for DPI Agents must be Passive mode in order to avoid potential problems or faults influencing the normal operational mode of ISP practitioners). In different network architectures, different kinds of DPI Agents are required to obtain different network information.

DPI Agents extract the Internet Access Information of IP devices, and sends the information to the IPLD via XML-based protocol. This procedure is called IP Location Measurement.

TABLE I.

TERMINATION INFORMATION VS. ACCESS INFORMATION

\begin{tabular}{|c|c|c|}
\hline & $\begin{array}{l}\text { Termination } \\
\text { Information }\end{array}$ & Access Information \\
\hline Definition & $\begin{array}{l}\text { Information } \\
\text { identifying a } \\
\text { particular terminal is } \\
\text { called Terminal } \\
\text { Information }\end{array}$ & $\begin{array}{l}\text { Information related to } \\
\text { how the terminal } \\
\text { accesses the network } \\
\text { is called Access } \\
\text { Information. }\end{array}$ \\
\hline Variability & Data seldom changes & $\begin{array}{l}\text { Data often changes, } \\
\text { especially in the } \\
\text { environment of } \\
\text { dynamic acquisition } \\
\text { of IP }\end{array}$ \\
\hline $\begin{array}{l}\text { Acquisition } \\
\text { mode }\end{array}$ & $\begin{array}{l}\text { Provided by network } \\
\text { administrator, also } \\
\text { known as } \\
\text { Provisioning Data. }\end{array}$ & $\begin{array}{l}\text { Obtained from } \\
\text { existing network } \\
\text { communication } \\
\text { equipment or } \\
\text { communication } \\
\text { protocols }\end{array}$ \\
\hline
\end{tabular}

\subsubsection{IP Location mapping}

The location of the targeted IP is inferred from the IP Location measured results, namely, integrating the Access Information with Termination Information to form an information chain of an IP Location (Figures 2 to 4). The actual Location, e.g. civic address, latitude and longitude, or range (wireless network), of the IP device in operation can be inferred from an IP and time.

For example, the DDA settled in an enterprise network environment (Figure 1) intercepts and analyzes DHCP packets in order to instantly obtain the Access Information required for IP Location (Access Information in this case includes MAC Address and IP (allocated by DHCP Server) of an IP device, and the network equipment (Switch/Slot/Port) connected to the IP device). The information is transferred to IPLD for data retention. The information chain of IP Location can be formed by combining the exchanger port number (Switch/Slot/Port), which is periodically maintained by an enterprise network administrator, with location or Terminal Information corresponding to the user, as shown in Figure 2.

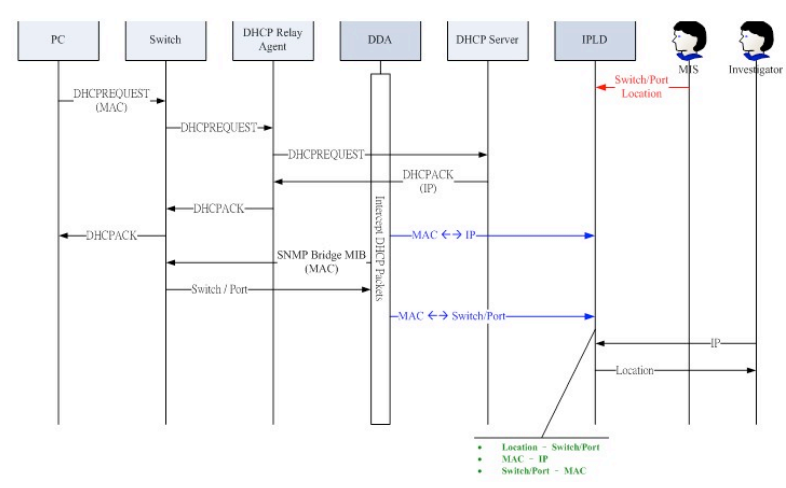

Figure 1. IP Location Mapping for Enterprise Network Flow Chart.

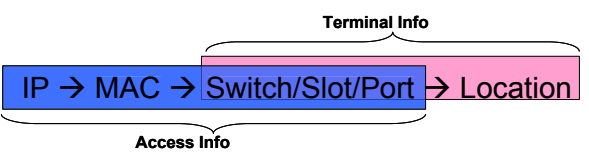

Figure 2. Correlation information chain of enterprise LAN network.

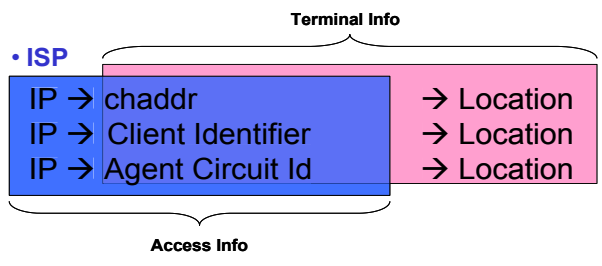

Figure 3. Correlation information chain of xDSL.

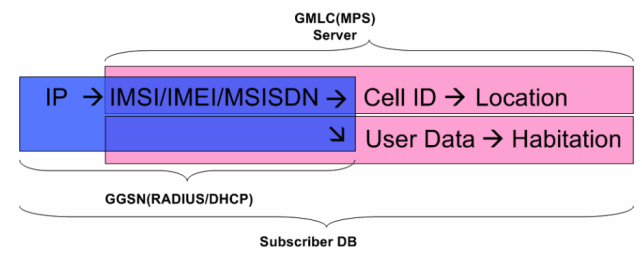

Figure 4. Correlation information chain of $3 \mathrm{G} / 3.5 \mathrm{G}$ network.

\subsection{IP Location system framework}

The proposed IP Location system framework is divided into an ISP side IP Location system and a Law Enforcement Agency (LEA) side IP Location inquiry system.

\subsubsection{ISP side IP Location system}


Whatever the network access technology is, most ISP back ends use DHCP or RADIUS to allocate IP to users. The proposed ISP side IP Location system framework is as shown in Figure 5. Basically, it is applicable to any ISP using DHCP or RADIUS to allocate IP to users.

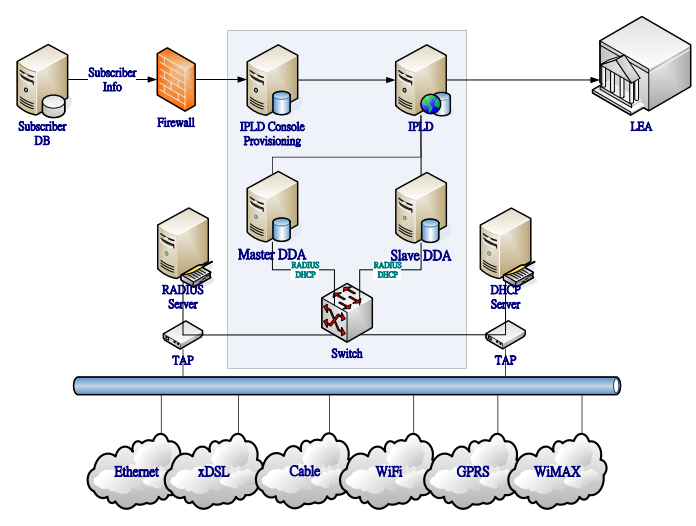

Figure 5. ISP side IP Location system framework.

The ISP side IP Location system framework contains the following modules to record the state and time interval for IP allocation:

Distributed DPI Agents (DDA): The DDA server contains DHCP packet analysis module (DHCP Dissector) and RADIUS packet analysis module (RADIUS Dissector) (Figure 6). All of DHCP/RADIUS packets to and from a DHCP/RADIUS server are duplicated by wiretap to the DDA. As shown in Figure 6, the DDA server contains a high speed network packet capture card, which captures all DHCP/RADIUS packets and temporarily stores them in the buffer of system. The DHCP Dissector and RADIUS Dissector inside the host instantly analyze and record the Access Information, including the IP allocated by a DHCP/RADIUS server, MAC Address, auxiliary number, dial-up account, NAS Identifier/NAS Port, circuit number, and use time (See TABLE II). Finally, the information is transmitted via XML-based protocol to the IPLD server. In order to guarantee high usability of the system and integrity of data interception, the proposed IP Location mechanism is built on the DDA architecture of dual independent operation. All intercepted DHCP/RADIUS packets will simultaneously be sent to the Master DDA and Slave DDA for packet analysis (Figure 5). Figure 7 shows the implementation of DDA in ADSL network DHCP access architecture. Figure 8 shows the implementation in a ADSL network RADIUS (PPPoE) access architecture. The Internet Access Information obtained by DDA is as shown in TABLE II.

Meanwhile, the ISP must periodically provide information related to user location (at least geo information), which is transmitted via firewall to the Data Provisioning module inside the IP Location system.

IP2Location Database (IPLD): in charge of three tasks:

1. Receipt of information for IP allocation, as sent from Master DDA and Slave DDA, and recorded in IPLD.

2. To be periodically synchronous with the user database at the ISP side, or as required, in order to obtain the most accurate user geo information (ex: in GSM or UMTS system, IPLD needs to inquire the system in charge of maintaining the real-time geo information of user, e.g. GMLC, regarding the physical address of user at that time). In order to guarantee the system safety of the ISP practitioner, the user databases of IPLD and ISP practitioners are separated by firewall, and only one-way data transmission from user database to IPLD host is allowed.

3. Reply to request for IP Location query, as sent from LEA, where the request for IP Location query is described by XML-based protocol.

\subsubsection{LEA side IP Location inquiry system}

The IP Location inquiry system, at the LEA side, consists of the following modules:

IP Location query portal: provides Web interface for inquiries regarding the user of an IP during a time interval, and the actual Location after the user's logon. This module sends a request for IP Location query to the IPLD at ISP side via dedicated line and XML-based protocol. When the IPLD query is completed, the query result is sent back to this module via XML-based protocol, which module receives the response and displays the result on GIS. The process for accessing the IP Location results of law enforcement is as shown in Figure 9.

Database server: For storing all records and results of IP Location query. The IP Location data maintained by the ISP side IPLD will not be completely copied to LEA. The records and results of query will be recorded in the database only if the user makes a request for IP Location query. This design mode aims to protect individual privacy. In addition, this database contains the IP ranges under the control of domestic and foreign ISP, as well as the information related to ISP. The correspondence table of IP ranges and schools in TANET is also stored in this database.

Storage facility: For storing user IP Location system query and results.

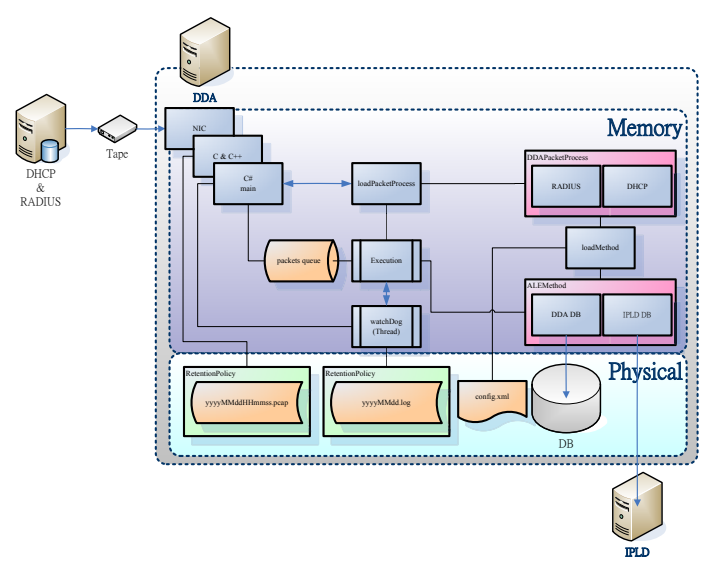

Figure 6. DDA software architecture design.

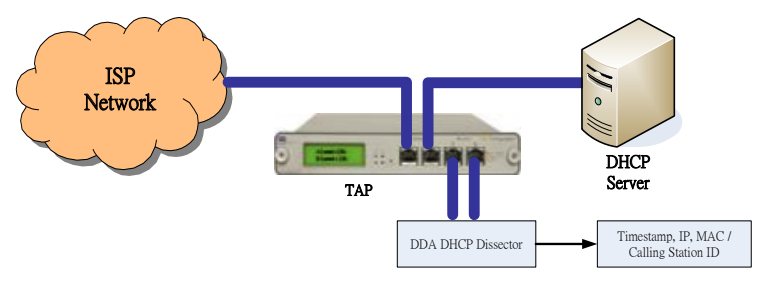

Figure 7. Schematic diagram of implementation of DDA in ADSL network-DHCP access architecture, DHCP packet interception. 


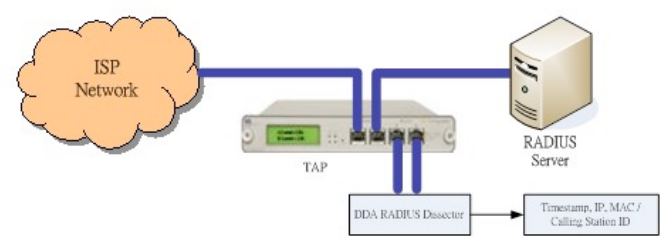

Figure 8. Schematic diagram of implementation of DDA in ADSL network RADIUS (PPPoE) access architecture, RADIUS packet interception.

TABLE II.

OBTAIN ACCESS INFORMATION VIA DISTRIBUTED DPI AGENTS

\begin{tabular}{|c|c|c|}
\hline & DHCP Dissector & RADIUS Dissector \\
\hline $\begin{array}{l}\text { Function } \\
\text { description }\end{array}$ & $\begin{array}{l}\text { Analyze DHCP packet, } \\
\text { obtain the coincidence } \\
\text { relation between IP and } \\
\text { hardware MAC } \\
\text { Address/auxiliary } \\
\text { number of Internet } \\
\text { connection tool }\end{array}$ & $\begin{array}{l}\text { Analyze RADIUS packet, } \\
\text { obtain the coincidence } \\
\text { relation between IP and the } \\
\text { Internet connection dial-up } \\
\text { account/PPPoE dial-up } \\
\text { account/auxiliary number } \\
\text { used by a cyber criminal }\end{array}$ \\
\hline Import & DHCP packet & RADIUS packet \\
\hline Export & $\begin{array}{l}\text { IP } \\
\text { MAC Address, } \\
\text { Auxiliary number, } \\
\text { and IP use time } \\
\quad \text { coincidence } \\
\quad \text { relation }\end{array}$ & $\begin{array}{l}\text { IP } \\
\text { Dial-up account, } \\
\text { PPPoE dial-up account, } \\
\text { Auxiliary number, } \\
\text { NAS Identifier/NAS Port, } \\
\text { and IP use time } \\
\text { coincidence relation }\end{array}$ \\
\hline
\end{tabular}

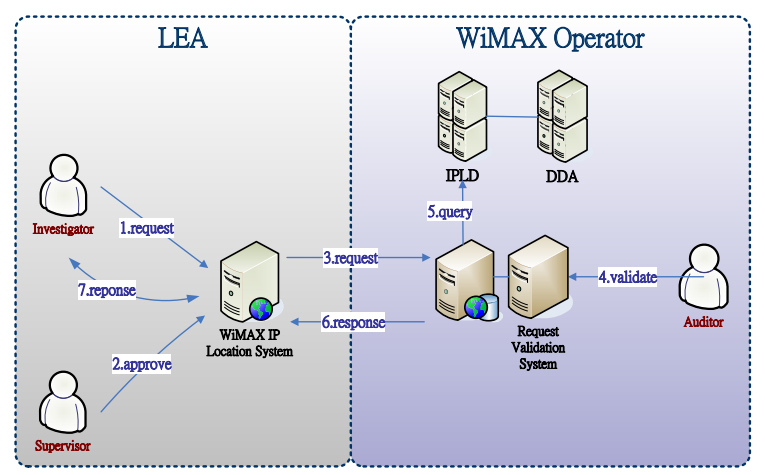

Figure 9. Process of accessing to IP Location results.

\section{IMPLEMENTATION AND ANALYSIS}

\subsection{Test environment and requirements}

The IP Location system, as proposed in this study, is implemented in the networks of four WISP providing WiMax Internet access service (Global Mobile Corp., FETnet, Tatung, VeeTIME) (Figure 10).

According to the Network Reference Model, as defined by the WiMAX Forum, the WiMAX network can be divided into ASN (Access Service Network) and CSN (Connectivity Service Network). ASN and CSN can be built and operated by the same or different operators. Although all current operators with WiMAX operating license in Taiwan plan to build and operate both of ASN and CSN, in order to render the design of the system framework in this study compatible with all probable network architectures, ASN and CSN are still regarded as independently operated individuals. Which is to say, in the architecture design, this study assumes that ASN and CSN are built and operated by different operators.

The DDA will be settled at the CSN side to intercept and analyze RADIUS packets accessing the AAA server. From the RADIUS packets intercepted by DDA, the dialup account of a WiMAX user, the MAC Address of a WiMAX device, BSID (Base Station ID), and IP, released to the device/user can be analyzed. DDA transfer the analyzed Access Information via XML-based protocol to IPLD.

IPLD receives the Access Information analyzed by the DDA server, which it stores in the database for subsequent query. In order to provide detailed user information, IPLD must be integrated with the user database at the WiMAX operator side by the Provisioning server. For the security of the network, as maintained and operated by the WiMAX operator, the WiMAX IP Location system is separated by a firewall from the operator maintained and operated network.

Although DDA can obtain the user dial-up account, MAC Address of the WiMAX device, BSID, and IP, by intercepting and analyzing the RADIUS packet, the actual Location (e.g. latitude and longitude) of WiMAX device) cannot be analyzed through the RADIUS packet. As the mapping between BSID and latitude and longitude is maintained by the ASN operator, in the WiMAX IP Location system, the IPLD server must obtain the geo information related to the base station in ASN via open interface or be integrated with the WiMAX device positioning system to obtain more accurate positioning information. As the construction cost of WiMAX device positioning system is high, this study will not comprehensively construct a WiMAX device positioning system in all WiMAX operators' networks. When the WiMAX IP Location system is integrated with the WiMAX device positioning system, the IP Location result will have higher accuracy (smaller than coverage of base station). Otherwise, the accuracy is identical to the coverage of the base station.

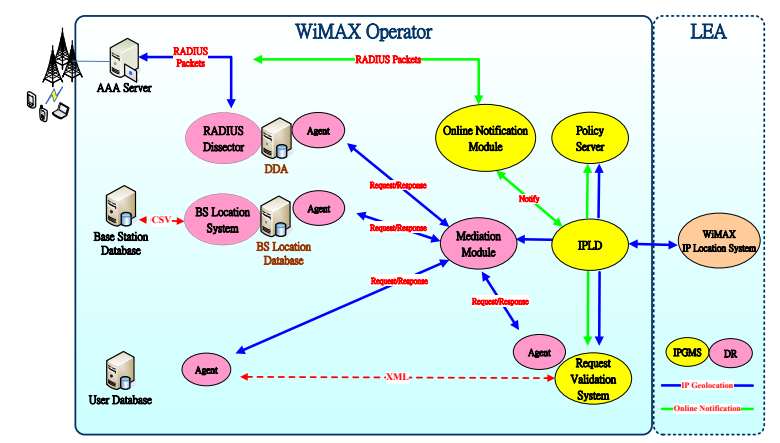

Figure 10. WiMax IP Location system modules.

\subsection{Test Procedure}

\subsubsection{Scenarios}

This section uses 10 actual Internet fraud cases, as provided by the High-Tech Criminal Center, Criminal Investigation Bureau of Taiwan, in order to evaluate the feasibility of the IP Location mechanism, as proposed in this paper. The criminals in the cases used IP as means of communication to avoid investigation (e.g. E-mail, VoIP, and MSN) (Figure 11). This study selects 32 criminals 


\section{DISTRIBUTED AGENT-BASED IP LOCATION SYSTEM FRAMEWORK DESIGN}

whose locations (tracking monitoring) have been mastered by LEA for verifying the feasibility of objects' IP Location and IP user individualization.

\subsubsection{IP Location Mapping and analysis}

The 122 IP Addresses obtained in the test period are used to validate the location result of the proposed IP Location mechanism, as compared with the physical location of the actual crime, in the Internet access via WiMAX, the IP Location result shows the "accuracy rate" is $100 \%$, and the Cell coverage (i.e. BSID) when the criminal connected to the Internet can be located. The error range varies with the planned coverage of the base station. For example, the WiMAX base station coverage has a radius of about $500 \mathrm{~m}$ in urban areas (Figures 13 and 15), and the historical actual trace of the Target Client can be reconstructed (Figure 14). The Access Information can be correlated with Terminal Information to link IP to Location (Figure 12, TABLEs III and IV) and Target Client (i.e. User Data, see Figure 12 and TABLE V).

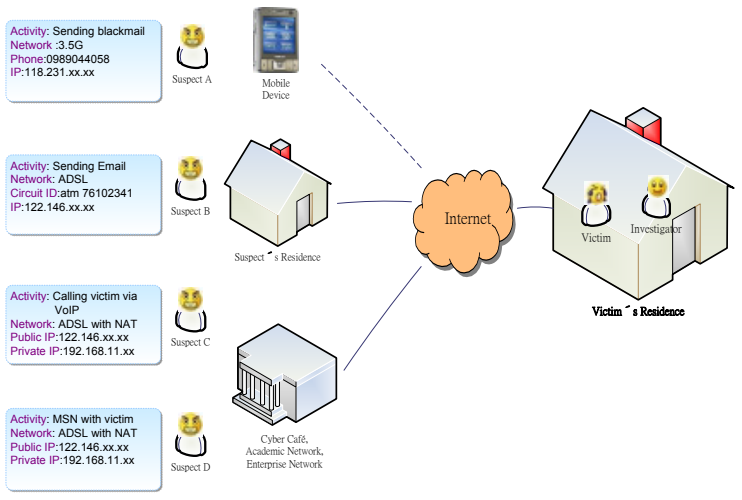

Figure 11. Schematic diagram of IP communication dodging detection.

TABLE III.

ACCESS INFORMATION AND TERMINAL INFORMATION FOR WIMAX NETWORKS

\begin{tabular}{|c|c|c|c|}
\hline $\begin{array}{l}\text { Request } \\
\text { for } \\
\text { location }\end{array}$ & $\begin{array}{c}\text { Source } \\
\text { host }\end{array}$ & Data included & $\begin{array}{c}\text { Integrated } \\
\text { data }\end{array}$ \\
\hline \multirow{2}{*}{$\begin{array}{l}\text { Real time } \\
\text { IP } \\
\text { Locating }\end{array}$} & $\begin{array}{c}\mathrm{AAA}+\mathrm{DSS} \\
\text { server }\end{array}$ & $\begin{array}{c}\mathrm{IP}<=>\text { Account } \\
\text { number/device number } \\
<=>\text { BSID }\end{array}$ & \multirow{2}{*}{$\begin{array}{l}\text { IP }<=>\text { Loca } \\
\text { tion result } \\
\text { (real-time) }\end{array}$} \\
\hline & $\begin{array}{c}\text { Base station } \\
\text { database }\end{array}$ & BSID $<=>$ Location & \\
\hline \multirow{3}{*}{$\begin{array}{l}\text { IP history } \\
\text { location }\end{array}$} & $\begin{array}{c}\text { AAA+DSS } \\
\text { server }\end{array}$ & $\begin{array}{c}\mathrm{IP}<=>\text { Account } \\
\text { number/device number }\end{array}$ & \multirow{3}{*}{$\begin{array}{c}\text { IP }<=>\text { Loca } \\
\text { tion } \\
\text { (history) }\end{array}$} \\
\hline & $\begin{array}{l}\text { Location } \\
\text { data } \\
\text { storage } \\
\text { system } \\
\end{array}$ & $\begin{array}{c}\text { Account } \\
\text { number/device number } \\
<=>\text { BSID }\end{array}$ & \\
\hline & $\begin{array}{c}\text { Base } \\
\text { station } \\
\text { database } \\
\end{array}$ & $\begin{array}{c}\text { BSID }<=>\text { Location } \\
\text { result }\end{array}$ & \\
\hline $\begin{array}{c}\text { Personal } \\
\text { data of } \\
\text { user }\end{array}$ & $\begin{array}{c}\text { User } \\
\text { database }\end{array}$ & $\begin{array}{c}\text { Account } \\
\text { number }<=>\text { name/ID } \\
\text { card/contact } \\
(\mathrm{Tel}) / \mathrm{mobile} / \text { Email/ad } \\
\text { dress } / . . .\end{array}$ & $\begin{array}{l}\text { Personal } \\
\text { data }\end{array}$ \\
\hline
\end{tabular}

TABLE IV.

BASE STATION DATA INTEGRATION

\begin{tabular}{|c|c|c|c|c|}
\hline Field Name & Type & Null & Description & Note \\
\hline BSID & Char(6) & $\mathrm{N}$ & BSID & \\
\hline CellName & $\begin{array}{c}\text { NYarchar2 } \\
\text { (64) }\end{array}$ & & $\begin{array}{l}\text { Base station } \\
\text { name }\end{array}$ & \\
\hline CellAddress & $\begin{array}{c}\text { NYarchar2 } \\
(256)\end{array}$ & $\mathrm{N}$ & $\begin{array}{l}\text { Base station } \\
\text { address }\end{array}$ & \\
\hline AntennaDirection & $\begin{array}{c}\text { Number } \\
(5,2)\end{array}$ & $\mathrm{N}$ & $\begin{array}{l}\text { Base station } \\
\text { direction, } \\
\text { default } 0\end{array}$ & \\
\hline Longitude & $\begin{array}{c}\text { Number } \\
(10,7)\end{array}$ & & $\begin{array}{l}\text { Longitude, } \\
\text { default } 1\end{array}$ & \\
\hline Latitude & $\begin{array}{c}\text { Number } \\
(10,7)\end{array}$ & & $\begin{array}{l}\text { Latitude, } \\
\text { default } 1\end{array}$ & \\
\hline IP & $\begin{array}{l}\text { Varchar2 } \\
(15)\end{array}$ & & $\begin{array}{l}\text { Base station IP } \\
\text { address }\end{array}$ & $\begin{array}{l}\text { Request } \\
\text { for device } \\
\text { location } \\
\end{array}$ \\
\hline DownTilt & $\begin{array}{l}\text { Number } \\
\text { (3) }\end{array}$ & & $\begin{array}{l}\text { Angle of } \\
\text { declination }\end{array}$ & $\begin{array}{l}\text { Request } \\
\text { for device } \\
\text { location }\end{array}$ \\
\hline PreambleIndex & $\begin{array}{l}\text { Number } \\
\text { (4) }\end{array}$ & & $\begin{array}{l}\text { Leading index } \\
\text { value, } \\
\text { composed of } \\
\text { ID Cell and } \\
\text { Segment }\end{array}$ & $\begin{array}{l}\text { Request } \\
\text { for device } \\
\text { location }\end{array}$ \\
\hline $\begin{array}{l}\text { BasicCIDUpper } \\
\text { Bound }\end{array}$ & $\begin{array}{l}\text { Number } \\
\text { (4) }\end{array}$ & & $\begin{array}{l}\text { Upper value of } \\
\text { Connection ID }\end{array}$ & $\begin{array}{l}\text { Request } \\
\text { for device } \\
\text { location }\end{array}$ \\
\hline $\begin{array}{l}\text { BasicCIDLowerB } \\
\text { ound }\end{array}$ & $\begin{array}{l}\text { Number } \\
\text { (4) }\end{array}$ & & $\begin{array}{l}\text { Lower value of } \\
\text { Connection ID }\end{array}$ & $\begin{array}{l}\text { Request } \\
\text { for device } \\
\text { location }\end{array}$ \\
\hline CenterFrequency & $\begin{array}{l}\text { Number } \\
\text { (10) }\end{array}$ & & $\begin{array}{l}\text { Transmission } \\
\text { power }(\mathrm{MHz})\end{array}$ & $\begin{array}{l}\text { Request } \\
\text { for device } \\
\text { location }\end{array}$ \\
\hline BandWidth & $\begin{array}{l}\text { Number } \\
\text { (10) }\end{array}$ & & $\begin{array}{l}\text { Bandwidth } \\
(\mathrm{MHz})\end{array}$ & $\begin{array}{l}\text { Request } \\
\text { for device } \\
\text { location }\end{array}$ \\
\hline LastModifyDT & Date & & $\begin{array}{l}\text { Date of last } \\
\text { update }\end{array}$ & $\begin{array}{l}\text { Request } \\
\text { for device } \\
\text { location }\end{array}$ \\
\hline
\end{tabular}

TABLE V.

USER DATA INTEGRATION

\begin{tabular}{|l|l|l|}
\hline \multicolumn{1}{|c|}{ Field } & \multicolumn{1}{|c|}{ Type } & \multicolumn{1}{c|}{ Description } \\
\hline Provider & String & Name of operator the user applies to \\
\hline Name & String & $\begin{array}{l}\text { Name of applicant user/name of applicant } \\
\text { user's unit }\end{array}$ \\
\hline String & $\begin{array}{l}\text { Account number of applicant user } \\
\text { Decoded Inner User ID (NAI) in WiMAX } \\
\text { environment }\end{array}$ \\
\hline MAC & String & $\begin{array}{l}\text { WiMAX billing account number, user } \\
\text { Roaming to billing codes used by other } \\
\text { practitioners }\end{array}$ \\
\hline BillingAddr & String & $\begin{array}{l}\text { WiMAX user's device hardware number } \\
\text { (MAC address) }\end{array}$ \\
\hline CustomerAddr & String & Applicant user's account address \\
\hline
\end{tabular}

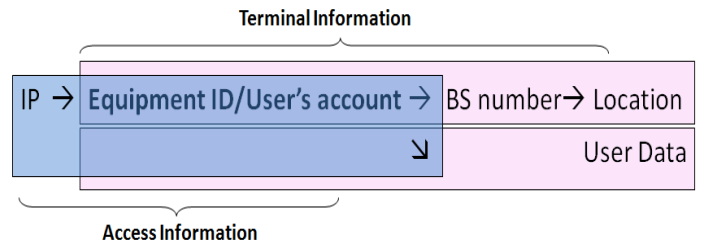

Figure 12. Correlation information chain of WiMAX networks. 


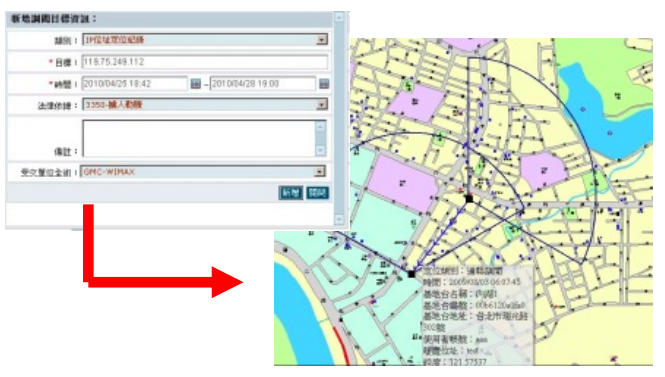

Figure 13. IP history location.

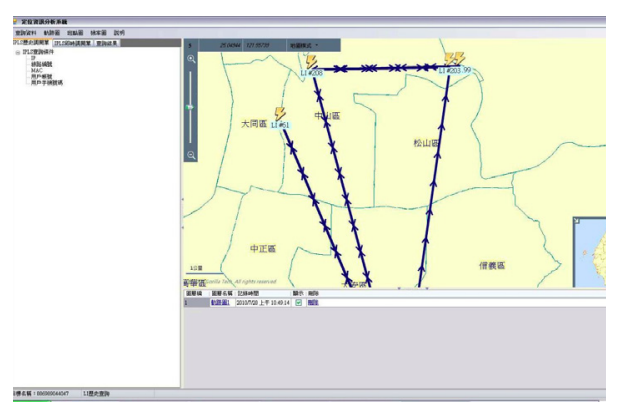

Figure 14. Track analysis of IP history location.

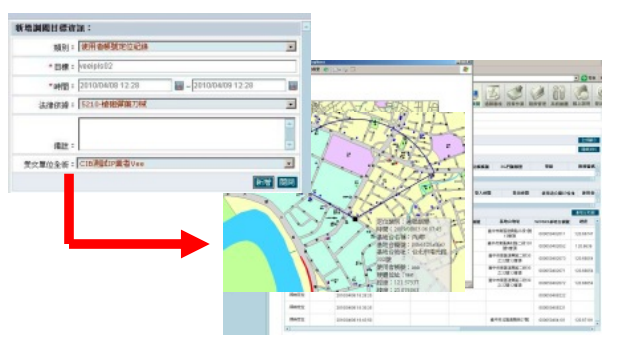

Figure 15. Real time IP Locating.

\section{CONCLUSIONS AND FUTURE WORKS}

The proposed IP Location mechanism is based on IP Location and Network Forensics concepts, which develop tracking and locating mechanisms on the Internet. The logic of IP Location and individualization is that in an environment of an integrated fixed network, mobile telecommunication network 3/3.5G, WiMAX, and next generation network IP Multimedia Subsystem (IMS), each related node in the network is confirmed, the DPI (Deep Packet Inspection) is in charge of accessing, copying, decoding, and saving necessary data retention for IP Location, in order to analyze the location of the IP Address and associatively identity IP users according to an IP Address, time, and information records, remaining from using IP services on the Internet.

The contributions of this study are, as follows. The proposed IP Location mechanism can be applied to targeted marketing, restrict digital content sales to authorized jurisdictions, and other security applications, such as credit card fraud, and could serve as part of an E911 system for voice over IP. The accuracy of IP Location has been increased from the current ISP-level and citylevel to a minimum $0 \mathrm{~m}$ error (Internet connection via fixed network), and the maximum error is Cell range (Internet connection via mobile network), which is low cost and without constructing reference nodes (landmarks), and actual use, to individualize the IP user.

This system is designed as an open IP Location system platform. The interoperability between systems is high, and the future development of the system will not be limited to a single access mode. In other words, any future access technology (e.g. LTE, Long Term Evolution), as long as it provides an IPLD server and supports XMLbased protocol, can be integrated into the IP Location system.

In terms of Implications of Practice, the proposed IP Location mechanism does not need to modify the protocols of an existing network, redesign a new router, or set numerous reference points, as it can be directly applied to the existing network, and can provide excellent accuracy. The research findings can be used as reference for various countries to develop Internet tracking.

In terms of the limitations of this study, the proposed IP Location system framework is only applicable for a domestic IP. In order to apply it to a global Internet location, various countries should have the same mechanism, and a centralized IP2Location Database (IPLD) should be established, in order to meet the requirements for global IP Location.

\section{REFERENCES}

[1] R. Moore, Cyber Crime, Investigating High-Technology Computer Crime, Anderson, 2005.

[2] W.G. Kruse and J.G. Heiser, Computer Forensics: Incident Response Essentials, Addison-Wesley Professional, 2002, p. 392.

[3] M. Ma, "Tabu marking scheme to speedup IP traceback," Computer Networks, vol. 50, no. 18, 2006, pp. 3536-3549. http://dx.doi.org/10.1016/j.comnet.2006.02.004

[4] Z. Gao and N. Ansari, "A practical and robust inter-domain marking scheme for IP traceback," Computer Networks, vol. 51, no. 3, 2007, pp. 732-750. http://dx.doi.org/10.1016/j.comnet. 2006.06.003

[5] G.H. Lai, C.M. Chen, B.C. Jeng, and W. Chao, "Ant-based IP traceback," Expert Systems with Applications, vol. 34, no. 4, 2008, pp. 3071-3080. http://dx.doi.org/10.1016/j.eswa.2007.06.034

[6] X.J. Wang and X.Y. Wang, "Topology-assisted deterministic packet marking for IP traceback," The Journal of China Universities of Posts and Telecommunications, vol. 17, no. 2, 2010, pp. 116-121. http://dx.doi.org/10.1016/S10058885(09)60456-8

[7] H. Aljifri, M. Smets, and A. Pons, "IP Traceback using header compression," Computers \& Security, vol. 22, no. 2, 2003, pp. 136-151. http://dx.doi.org/10.1016/S0167-4048(03)00212-8

[8] J. Liu, Z.J. Lee, Y.C. Chung, "Dynamic probabilistic packet marking for efficient IP traceback," Computer Networks, vol. 51, no. 3, 2007, pp. 866-882. http://dx.doi.org/10.1016/j.comnet. 2006.06.009

[9] E. Hilgenstieler, E.P. Duarte Jr., G. Mansfield-Keeni, and N. Shiratori, "Extensions to the source path isolation engine for precise and efficient log-based IP traceback," Computers \& Security, vol. 29, no. 4, 2010, pp. 383-392. http://dx.doi.org/10.1016/j.cose.2009.12.011

[10] A. Castelucio, A. Tadeu, A. Gomes, A. Ziviani, and R.M. Salles, "Intra-domain IP traceback using OSPF," Computer Communications, vol. 35, no. 5, 2012, pp. 554-564. http://dx.doi.org/10.1016/j.comcom.2010.08.010

[11] J. Luo, X. Wang, M. Yang, "An interval centroid based spread spectrum watermarking scheme for multi-flow traceback," Journal of Network and Computer Applications, vol. 35, no. 1, 2011, pp. 60-71. http://dx.doi.org/10.1016/j.jnca.2011.03.003

[12] L. Li and S.B. Shen, "Packet track and traceback mechanism against denial of service attacks," The Journal of China Universities of Posts and Telecommunications, vol. 15, no. 3, 2008, pp. 51-58. http://dx.doi.org/10.1016/S1005-8885(08)60107$\underline{7}$ 


\section{SPECIAL FOCUS PAPER \\ DiSTRIBUTED AGENT-BASED IP LOCATION SYSTEM FRAMEWORK DESIGN}

[13] J. Luo, X. Wang, and M. Yang, "An interval centroid based spread spectrum watermarking scheme for multi-flow traceback," Journal of Network and Computer Applications, vol. 31, no. 1, 2012, pp. 60-71. http://dx.doi.org/10.1016/j.jnca.2011.03.003

[14] Y. Kim, A. Helmy, "CATCH: A protocol framework for crosslayer attacker traceback in mobile multi-hop networks," Ad Hoc Networks, vol. 8, no. 2, 2010, pp. 193-213. http://dx.doi.org/10.1016/j.adhoc.2009.07.002

[15] A. Durresi, V. Paruchuri, and L. Barolli, "Fast autonomous system traceback," Journal of Network and Computer Applications, vol. 32, no. 2, 2009, pp. 448-454. http://dx.doi.org/10.1016/ j.jnca.2008.02.019

[16] E. Katz-Bassett, J. John, A. Krishnamurthy, D. Wetherall, T. Anderson, and Y. Chawathe, "Towards IP geolocation using delay and topology measurements," Proceedings of the 6th ACM SIGCOMM conference on Internet measurement, pp. 71-84, 2006.

[17] J.A. Muir and P.C. Oorschot, Internet Geolocation and Evasion, Citeseer, 2006.

[18] V. Padmanabhan and L. Subramanian, "An investigation of geographic mapping techniques for internet hosts," Proceedings of the 2001 conference on Applications, technologies, architectures, and protocols for computer communications, pp. 173-185, 2001.

[19] B. Gueye, A. Ziviani, M. Crovella, and S. Fdida, "Constraintbased geolocation of internet hosts," IEEE/ACM Transactions on Networking, vol. 14, no. 6, 2006, pp. 1219-1232. http://dx.doi.org/10.1109/TNET.2006.886332

[20] B. Wong, I. Stoyanov, and E. Sirer, "Octant: a comprehensive framework for the geolocalization of internet hosts," Proceedings of the 4th USENIX conference on Networked systems design \& implementation, pp. 313-326, 2007.

[21] D. Li, J. Chen, C. Guo, Y. Liu, J. Zhang, Z. Zhang, Y. Zhang, "IPgeolocation mapping for involving moderately-connected internet regions," Project participation from Microsoft Research, 2009.

[22] Sarangworld Traceroute http://www.sarangworld.com/TRACEROUTE/.

[23] P.T. Endo and D.F.H. Sadok, "Whois based golocation: a strategy to geolocate Internet hosts," Proceedings of the 2010 24th IEEE International Conference on Advanced Information Networking and Applications, pp. 408-413, 2010. http://dx.doi.org/10.1109/ AINA.2010.39

[24] D.C. Vixie, P. Goodwin, and T. Dickinson, "A means for expressing location information in the domain Name System," IETF Network Working Group, RFC-1876, 1996.

[25] K. Harrenstien, M. Stahl, E. Feinler, "NICNAME/WHOIS," IETF Network Working Group, RFC-954, 1985.

[26] M. Dawson, "The internet location services model," Computer Communications, vol. 31, no. 6, 2008, pp. 1104-1113. http://dx.doi.org/10.1016/j.comcom.2008.01.012

[27] W. Stallings, Cryptography and Network Security - Principles and Practices, 4th ed, Pearson Education International, 2006.

\section{AUTHORS}

Feng-Yu Lin received his Ph.D. degree from the National Chiao Tung University, Taiwan, Republic of China, in 2004. Currently, he is working towards the second Ph.D. degree in the Department of Information Management, National Taiwan University. His research interests include communication/network forensics, data mining, and information/network security. (e-mail: d95725003@ntu.edu.tw).

Yeali S. Sun received her BS from the Computer Science and Information Engineering department of National Taiwan University in 1982, and MS and Ph.D. degrees in Computer Science from the University of California, Los Angeles in 1984 and 1988, respectively. From 1988 to 1993, she was with Bell Communications Research Inc. (Bellcore; now Telcordia). In August 1993, she jointed National Taiwan University and is currently a professor of the Department of Information Management. Her research interests are in the area of wireless networks, Quality of Service and pricing, Internet security and forensics, scalable resource management and business model in cloud services and performance modeling and evaluation.

Meng Chang Chen received his B.S. and M.S. degrees in Computer Science from National Chiao Tung University, Taiwan, in1979 and 1981, respectively, and the Ph.D. degree in Computer Science from the University of California, Los Angeles, in 1989. He was with AT\&T Bell Labs from 1989 to 1992 . He is a Research Fellow of Institute of Information Science, Academia Sinica, Taiwan and have served as Deputy Director of the institute for 5 five years. His current research interests include wireless access network, QoS networking, computer and network security, information retrieval, and data and knowledge engineering.

Submitted, July 25, 2013. Published as resubmitted by the authors on August, 31, 2013. 